\title{
Damage to Pseudohyphal Forms of Candida albicans by Neutrophils in the Absence of Serum In Vitro
}

\author{
Richard D. Diamond, Raymond Krzesicki, and Wellington Jao, Infectious \\ Disease Division, Departments of Medicine, Michael Reese Hospital and \\ the University of Chicago-Pritzker School of Medicine, and Department \\ of Pathology, Michael Reese Hospital, Chicago, Illinois 60616
}

\begin{abstract}
A B S T RACT Large forms of Candida are characteristically present in invasive lesions and are often cleared by host defenses. Therefore, an in vitro system was developed to study interactions between leukocytes and pseudohyphae. By light, phase contrast, and electron microscopic observations, in the absence of serum, neutrophils attached to and spread over the surfaces of partially ingested pseudohyphae, which then appeared damaged. Using a new assay which measured neutrophil-induced inhibition of uptake of $\left[{ }^{14} \mathrm{C}\right]$ cytosine by Candida, damage to Candida in the absence of serum was $53.04 \pm 2.96 \%$ by neutrophils from 27 normal subjects. With serum, damage to Candida increased because of opsonization by low levels of anti-Candida immunoglobulin $G$ in normal sera. Damage to Candida was inhibited by colchicine, cytochalasin B, and 2-deoxyglucose, which interfered with spreading of neutrophils over the surfaces of Candida. Dibutyryl cyclic AMP, theophylline, and isoproterenol also inhibited damage to Candida. Hydrocortisone was inhibitory in levels $\left(\begin{array}{ll}10 & \mu \mathrm{M}\end{array}\right)$ achievable with pharmacologic doses in man. Light, fluorescence, and electron microscopy indicated that neutrophils degranulated after contact with Candida. Quantitative studies revealed only a minimal increase in specific release of lysosomal enzymes from azurophil granules, but much greater release of lysozyme from specific granules. Candida activated neutrophil oxidative microbicidal mechanisms, as shown by iodination of Candida by neutrophils, and chemiluminescence from neutrophils interacting with Candida.
\end{abstract}

Preliminary findings were presented in part at the Annual Meeting of the American Federation for Clinical Research, May 1977. Clin. Res. 25: 374. (Abstr.), and at the Annual Meeting of the American Society for Microbiology, May 1977.

Dr. Diamond is a recipient of Research Career Development Award 00055 from the National Institute of Allergy and Infectious Disease, National Institutes of Health.

Received for publication 11 July 1977 and in revised form 19 September 1977.
Unlike live Candida, killed Candida did not induce chemiluminescence, were not iodinated, and did not attach to neutrophils by microscopy. Like Candida pseudohyphae, contact between neutrophils and hyphal forms of Aspergillus and Rhizopus occurred in the absence of serum. This did not occur with Cryptococcus neoformans, an encapsulated yeast, and was low with Candida yeasts. These findings indicate that neutrophils can recognize and attach to Candida pseudohyphae, then damage the Candida. This may represent a general reaction between neutrophils and large forms of fungi. Though the size of the organisms precludes complete ingestion, neutrophil oxidative microbicidal mechanisms are activated, and preferential release of contents of specific granules appears to occur.

\section{INTRODUCTION}

Candidiasis is the most commonly observed systemic mycosis in the compromised host, constituting a significant percentage of all infections and of causes of death in this population (1-3). Within invasive lesions, pseudohyphal and hyphal forms of Candida are more prominent than yeasts $(4,5)$, and must be cleared if the host is to survive. Pseudohyphal and hyphal forms of Candida can be cleared in at least some systemic infections in experimental animals (6), and in man $(1-3,7,8)$. Reproducible quantitative determinations of viability of hyphae and pseudohyphae have been difficult. Most in vitro studies have concentrated on the ability of leukocytes to ingest and kill yeasts. Such studies (9-13), as well as the observed clinical association of neutropenia with disseminated candidiasis (14), suggest that neutrophils are important in host defenses against systemic candidiasis.

The interactions of leukocytes with filamentous forms of fungi may not necessarily correlate directly with observations on phagocytosis and killing of yeasts $(9-12,15)$, especially because hyphae and pseudohyphae 
are too large to be ingested completely. We describe a new leukocyte mechanism where, in the absence of serum opsonins (including antibody and complement), human neutrophils partially ingested and damaged Candida albicans pseudohyphae.

\section{METHODS}

Candida and other fungi. An isolate of Candida albicans orginally obtained from a patient with systemic candidiasis was maintained in yeast phase on Sabouraud's agar. For germination, yeasts were washed in phosphate-buffered saline and suspended in Eagle's minimal essential medium, which had been supplemented with nonessential amino acids (Grand Island Biological Co., Grand Island, N. Y.) (16, 17). After $4 \mathrm{~h}$ of incubation at $37^{\circ} \mathrm{C}$, and at $20-30-\mathrm{min}$ intervals thereafter, aliquots were removed and examined for germ tube formation by phase contrast microscopy. When $\geq 95 \%$ of cells had formed germ tubes $\geq 30 \mu \mathrm{M}$ in length, test tubes were stored at $4^{\circ} \mathrm{C}$. Candida used immediately or those stored at $4^{\circ} \mathrm{C}$ for $18 \mathrm{~h}$ gave comparable results. For some experiments, Candida were killed by heating at $100^{\circ} \mathrm{C}$ (in a boiling water bath) for $1 \mathrm{~h}$ or by exposure to ultraviolet light for $16 \mathrm{~h}$. Samples were plated on Sabouraud's agar and observed for $72 \mathrm{~h}$ to verify that no live organisms remained. Before incubation with leukocytes, live or killed Candida were washed three times and resuspended in Hanks' balanced salt solution (HBSS, ${ }^{1}$ Grand Island Biological Co.). Patient isolates of Aspergillus fumigatus and Rhizopus oryzae were supplied by Dr. John Rippon, University of Chicago, Chicago, Ill., and a small capsule isolate of Cryptococcus neoformans by Dr. John E. Bennett, National Institutes of Health, Bethesda, Md. Aspergillus and Rhizopus spores were germinated and washed as described above for $\mathrm{Can}$ dida. Cryptococci were heat-killed and washed following the same procedure as with Candida.

Leukocytes. Human peripheral venous blood anticoagulated with preservative-free heparin (Connaught Laboratories, Toronto, Ontario, Canada) was obtained from normal volunteer subjects. Neutrophils were separated by sedimentation with $3 \%$ dextran (average molecular weight 250,000; Pharmacia Fine Chemicals, Div. of Pharmacia, Inc., Piscataway, N. J.) in saline. Remaining erythrocytes were lysed in an ammonium chloride-Tris buffer solution (18). Leukocytes were washed in modified Hanks' solution (19) which contained no calcium or magnesium, then suspended in HBSS. For some studies, more purified preparations of neutrophils were obtained by using Hypaque (sodium and meglumine diatrizoates; Winthrop Laboratories, New York) and Ficoll (Pharmacia Fine Chemicals) followed by dextran sedimentation as described by Böyum (20).

Serum. Serum was obtained from each normal volunteer donor at the same time as blood for leukocytes, and from two subjects with rheumatoid arthritis (rheumatoid factor titers $1: 320$ and $1: 1,280$ by latex fixation). Sera were used fresh, or after storage at $-70^{\circ} \mathrm{C}$ or heating at $56^{\circ} \mathrm{C}$ for $60 \mathrm{~min}$.

Immunoglobulins. Two commercial preparations of immunoglobulin G (IgG) were obtained, one $>95 \%$ pure (Fraction II, Pentex Company, Kankakee, Ill.) and one $>98 \%$ pure (Mann Research, Inc., New York). IgG was also purified to give a single line on immunoelectrophoresis using minor modifications in the method of Stanworth (21). For some experiments, IgG was aggregated by heating for $20 \mathrm{~min}$ at $63^{\circ} \mathrm{C}$.

${ }^{1}$ Abbreviation used in this paper: HBSS, Hanks' balanced salt solution.
Detection of anti-Candida immunoglobulins. Tests for anti-Candida immunoglobulins were performed on sera and immunoglobulin preparations used in these studies. Agglutinins and precipitins were detected using slight modifications in the technique of Preisler et al. (22). For detection of antibodies by indirect fluorescence, live Candida albicans. were incubated with sera, stained with goat anti-human IgG conjugated with fluorescein isothiocyanate (Microbiological Associates, Inc., Bethesda, Md.), washed and examined for fluorescence (graded from 0 to $4+$ ).

Radioisotope assays for metabolic activity of Candida. Suspensions containing $1 \times 10^{6}$ Candida albicans pseudohyphae and $1 \times 10^{6}-2 \times 10^{7}$ neutrophils in HBSS were placed in 15-ml plastic centrifuge tubes (Corning Glass Works, Corning, N. Y), and brought to $1 \mathrm{ml}$ total volume with HBSS. Triplicate tubes were placed in a rotator (Scientific Industries, Inc., Springfield, Mass.) and incubated at $37^{\circ} \mathrm{C}$ for timed intervals. Additional tubes were added to permit removal of aliquots for microscopic observations. To end the incubation, $0.25 \mathrm{ml}$ of $2.5 \%$ sodium deoxycholate was added to each tube. This induced lysis of leukocytes without damage to Candida cells (26). Control tubes contained only Candida pseudohyphae, but neutrophils were added just before deoxycholate. After lysis of neutrophils, remaining Candida were centrifuged, then washed twice in distilled water, and once in yeast nitrogen base broth which had been supplemented to contain $1 \%$ dextrose and $0.15 \%$ asparagine. Radioisotopically labeled compounds, including $\left[{ }^{14} \mathrm{C}\right]$ cytosine $(59-61 \mathrm{mCi} / \mathrm{mmol}),\left[{ }^{3} \mathrm{H}\right]$ mannose $(2 \mathrm{Ci} / \mathrm{mmol})$, and $\left[{ }^{3} \mathrm{H}\right]$ glucose $(1.1 \mathrm{Ci} / \mathrm{mmol}$ ) (Amersham/Searle Corp., Arlington Heights, Ill.) were diluted in supplemented yeast nitrogen base broth, but glucose supplementation was omitted in all studies were $\left[{ }^{3} \mathrm{H}\right]$ glucose or $\left[{ }^{3} \mathrm{H}\right]$ mannose were used. The optimum dose, time period, and temperature for incubation were determined for $\left[{ }^{14} \mathrm{C}\right]$ cytosine $(0.25 \mu \mathrm{Ci}$ and $1-\mathrm{h}$ incubation at $\left.30^{\circ} \mathrm{C}\right)$, as well as for $\left[{ }^{3} \mathrm{H}\right]$ mannose and $\left[{ }^{3} \mathrm{H}\right]$ glucose $\left(2.0 \mu \mathrm{Ci}\right.$ and $2 \mathrm{~h}$ at $\left.30^{\circ} \mathrm{C}\right)$. Candida were then separated and washed free of unbound radioisotope by using an automated, multiple-sample harvester (Otto Hiller Co. Madison, Wis.). Filters containing Candida were air-dried overnight, then placed in scintillation vials with $8 \mathrm{ml}$ Aquasol, (New England Nuclear, Boston, Mass.) and counted in a liquid scintillation counter. The neutrophil-induced percentage of reduction in uptake of isotope by Candida was calculated from (mean counts per minute in control tubes - mean counts per minute in experimental tubes $) /($ mean counts per minute in control tubes) $\times 100$. In some studies, instead of reduction of uptake in Candida, release of radioisotopes from prelabeled Candida was measured. For measurement of radioisotope release, Candida pseudohyphae in yeast nitrogen base broth supplemented as described above were incubated at $30^{\circ} \mathrm{C}$ for $1 \mathrm{~h}$ for labeling with $0.25 \mu \mathrm{Ci}$ $\left[{ }^{14} \mathrm{C}\right]$ cytosine, and $2 \mathrm{~h}$ for labeling with $\left[{ }^{3} \mathrm{H}\right]$ mannose. After washing three times in $\mathrm{HBSS}$, Candida were resuspended in $\mathrm{HBSS}$ and incubated with neutrophils at $37^{\circ} \mathrm{C}$ as described above. After $2 \mathrm{~h}$, Candida were pelleted by centrifugation at $600 \mathrm{~g}$. The supernate and pellet were then removed separately for scintillation counting. The total counts per minute in samples were determined from the sums of counts per minute in supernates and pellets of triplicate tubes. The percentage of isotope released was then determined by the (counts per minute in the supernatant)/(total counts per minute in supernatant plus pellet) $\times 100$.

Inhibitors. In some studies, inhibitors of neutrophil function were added during incubations. In others, neutrophils were preincubated with inhibitors for $20 \mathrm{~min}$ before the addition of Candida, and inhibitors remained in the media for the duration of the incubation with Candida. Unless 
otherwise specified, inhibitors were obtained from Sigma Chemical Co. (St. Louis, Mo.). Cytochalasin B was dissolved in dimethyl sulfoxide. Controls contained dimethyl sulfoxide without cytochalasin B, diluted comparably in HBSS. Colchicine was dissolved and directly diluted in HBSS, as were cyclic AMP, theophylline, and isoproterenol. For experiments using 2-deoxyglucose, glucose was excluded from HBSS, and controls contained 2-deoxyglucose plus glucose at 10 times the concentration of the 2-deoxyglucose. For studies of the effects of steroid hormones, their precursors, and metabolites on neutrophil function, the following compounds were dissolved in absolute ethanol: hydrocortisone, testosterone, estriol, androsterone, progesterone, dehydroisoandrosterone, and $17 \alpha$-hydroxyprogesterone. Control tubes included absolute ethanol diluted comparably to the above compounds which had been originally dissolved in ethanol.

Microscopic observations. At times intervals during the incubation of Candida with neutrophils, aliquots were removed for continuous observation under phase contrast microscopy using a stage incubator (Incustage, Lab-Line Instruments, Inc., Melrose Park, Ill.), and for staining using Wright-Giemsa. Trials of visual methods for determination of Candida viability were made after lysis of neutrophils using deoxycholate. Dye exclusion using methylene blue was performed on pseudohyphae exactly as described by Lehrer and Cline (23), and Giemsa staining as outlined by Lehrer (9). Viability of neutrophils was determined before and after incubation with Candida using exclusion of $0.1 \%$ trypan blue. In selected experiments, neutrophils were labeled with ${ }^{51} \mathrm{Cr}(24)$, and release of ${ }^{51} \mathrm{Cr}$ during incubations was measured. Degranulation of neutrophils was observed under phase contrast microscopy, and by fluorescence microscopy after staining of granules with a 1:100,000 dilution of acridine orange in HBSS according to the method of Allison (25) and D'Arcy Hart and Young (26). For electron microscopic studies of neutrophil degranulation, the method of Armstrong and D'Arcy Hart (27) was used with slight modifications. Neutrophil granules were labeled with $10 \mathrm{mg} / \mathrm{ml}$ ferritin (twice recrystallized cadmium free; Pentex Company) for $2.5 \mathrm{~h}$ at $37^{\circ} \mathrm{C}$, washed three times in HBSS, and incubated with Candida in the usual way.

Four electron microscopy, pellets containing Candida and neutrophils were fixed in $2.5 \%$ glutaraldehyde solution overnight. After washing overnight in cacodylate-buffered solution, pellets were postfixed in $2 \%$ osmium tetroxide for $2 \mathrm{~h}$. They were then dehydrated in increasing, graded concentrations of ethanol, and embedded in Epon. Thin sections were cut with diamond knives on an automatic Porter-Blum ultramicrotome (DuPont Instruments, Sorvall Operations, Newtown, Conn.). After staining with uranyl acetate and lead citrate, sections were mounted on carboncoated copper grids, examined with an RCA $3 \mathrm{H}$ electron microscope (Special Products Div., RCA Corp., Cherry Hill, N. J.) and photographed.

Iodination of Candida by neutrophils. The fixation of iodide to Candida (trichloroacetic acid-precipitable iodide) by neutrophils attaching to the surface of pseudohyphae was measured by the method of Klebanoff and Clark (28), with the following modifications. In addition to $\mathrm{pH} 7.4$ sodium phosphate buffer with added potassium, calcium, and magnesium salts, for optimum conditions, the reaction mixtures in triplicate or quadruplicate tubes contained $1 \times 10^{7}$ neutrophils, $5 \times 10^{6}$ Candida, or other fungi, but no serum unless otherwise stated. The optimum concentration of ${ }^{125} \mathrm{I}$ $\mathrm{Na}$ was found to be $0.5 \mu \mathrm{M}$, containing $0.2 \mu \mathrm{Ci}{ }^{125} \mathrm{I}$, with a 1-h incubation time.

Chemiluminescence by neutrophils attached to Candida pseudohyphae. Chemiluminescence was measured in a Beckman Model LS 230 liquid scintillation counter (Beckman Instruments, Inc., Electronic Instruments Div., Schiller Park, IIl.) as described by Stjernholm et al. (29). Vials contained $1 \times 10^{7}$ Candida in HBSS, or HBSS alone. Unless otherwise noted, reaction mixtures contained no serum.

Release of enzymes from neutrophils. Enzyme assays were kindly performed by Dr. Philip Davies and his colleagues (Department of Inflammation and Arthritis, Merck Institute for Research, Rahway, N. J.). $\beta$-Glucuronidase was assayed by the method of Talalay et al. (30), using phenolphthalein glucuronate (Sigma Chemical Co.) as substrate. $N$-acetyl- $\beta$-D-glucosaminidase was assayed according to the method of Woolen et al. (31), using $p$-nitrophenyl- $N$ acetyl- $\beta$-D-glucosaminidase as substrate. Lactate dehydrogenase was quantitated by assay of the change of optical density at $340 \mathrm{~nm}$ of NADH being oxidized to NAD by the conversion of pyruvate to lactate. Lysozyme was measured by using Micrococcus lysodeikticus, according to the method of Parry et al. (32).

Statistical methods. Means and SEM were compared using two sample T tests (33).

\section{RESULTS}

Microscopic observations of the interaction of Candida albicans pseudohyphae with neutrophils. Preliminary observations using light, phase contrast, and fluorescence microscopy suggested that neutrophils attached to pseudohyphae in the absence of serum, spread over pseudohyphal surfaces, and degranulated, resulting in altered Candida morphology. To extend these findings, electron micrographs were prepared from samples obtained at timed intervals during incubations of neutrophils with Candida pseudohyphae. Normal Candida morphology was apparent at the start of incubations (Fig. 1). By $20 \mathrm{~min}$ of incubation, neutrophils had spread over the surfaces and around Candida, and degranulation of neutrophils over the Candida surface was evident as shown in studies where neutrophil lysosomes were labeled by incubation with ferritin. Ferritin was specifically released by neutrophils over the surfaces of pseudohyphae (Fig. 2). By $1 \mathrm{~h}$ of incubation, damage to the Candida was apparent, as there were striking changes in the cell wall and internal morphology (Fig. 3), compared with normal Candida (Fig. 1), even though Candida were not completely ingested by neutrophils. Candida which were not in close contact with neutrophils had no apparent alterations in morphology.

To quantitate this apparent damage to Candida pseudohyphae by neutrophils, several staining techniques for light microscopy were used. These included methylene blue vital staining of Candida, and Giemsa staining of fixed specimens. As expected, these procedures were useful for Candida yeasts; unfortunately, they did not provide reproducible results with Candida pseudohyphae. Similarly, tube dilutions and plate counts were extremely variable and not reproducible, because of clumping of pseudohyphae. 


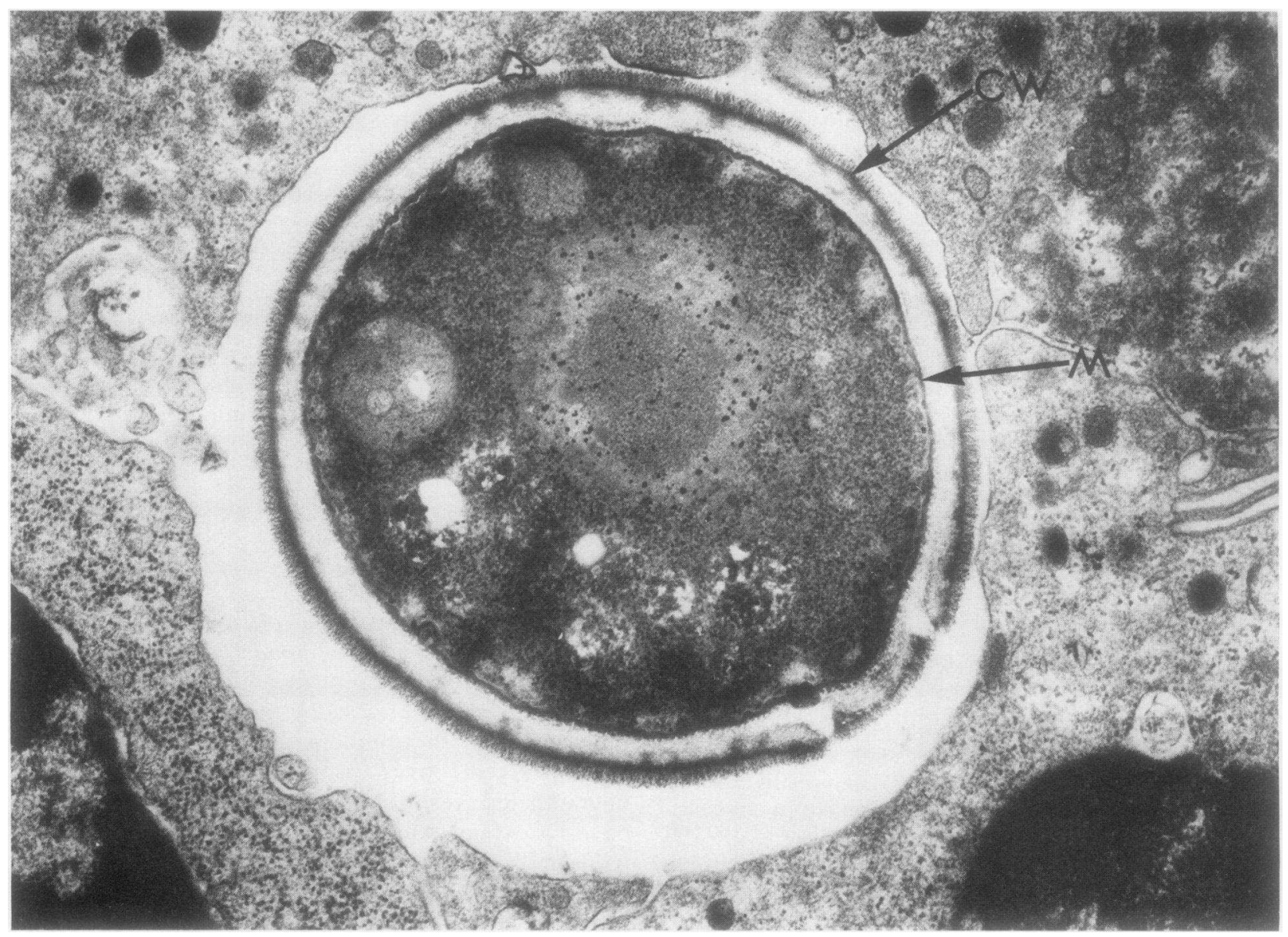

FIGURE 1 Electron micrograph showing normal Candida albicans pseudohyphal morphology seen in transverse section surrounded by neutrophils, at the start of an experiment. Cell wall $(\mathrm{CW})$ and cell membrane $(\mathrm{M})$ are shown by arrows, and internal structures are identifiable. Magnification $\times 35,910$.

Radioisotope assays for metabolic activity of Candida. Because routine methods for quantitating viability of fungi gave inconsistent results, use of radiolabeled compounds was investigated as a method which might permit quantitation of viability of Candida pseudohyphae before and after incubation with leukocytes. Experiments included the effects of neutrophils upon both reduction of uptake of radioisotopes by Candida, as well as release of radioisotopes from Candida during incubations (Fig. 4). With a short incubation time (1-2h), percentage release of $\left[{ }^{14} \mathrm{C}\right]$ cytosine or $\left[{ }^{3} \mathrm{H}\right]$ mannose was smaller than reduction in uptake. Prolongation of the incubation time resulted in growth of Candida and in consistent results. Reduction of uptake of $\left[{ }^{14} \mathrm{C}\right]$ cytosine proved a reproducible method, which correlated with reduction of uptake of $\left[{ }^{3} \mathrm{H}\right]$ mannose and glucose, as well as microscopic observations. Uptake of $\left[{ }^{14} \mathrm{C}\right]$ cytosine by Candida was linear over a 3-log range, from $1 \times 10^{4}$ to $1 \times 10^{7}$ live organisms. A ratio of
10 neutrophils: 1 Candida and a $1 \mathrm{~h}$ incubation time were optimum. In 40 experiments using neutrophils from 27 subjects under optimum conditions (Fig. 4), controls (Candida, which leukocytes added at the end of incubations) took up 56,654 $\pm 2,806 \mathrm{cpm}$ (mean $\pm \mathrm{SEM})$ of $\left[{ }^{14} \mathrm{C}\right]$ cytosine. There was a $10.9 \%$ range of variation within triplicates. Results were comparable in experimental tubes where leukocytes and Candida were incubated together. To determine whether metabolic damage was reversible, $\left[{ }^{14} \mathrm{C}\right]$ cytosine uptake was measured over $3 \mathrm{~h}$ immediately after lysis of leukocytes, and Candida were stored at $4^{\circ} \mathrm{C}$ for 4 and $18 \mathrm{~h}$. In four experiments, uptake of $\left[{ }^{14} \mathrm{C}\right]-$ cytosine did not increase at 4 and $18 \mathrm{~h}$ over baseline values (mean $-2.8 \%$, range -11.2 to $+3.4 \%$ ), but increased $20.3-38.7 \%(P<0.025)$ for control Candida where leukocytes were added just before deoxycholate lysis.

Opsonization of live Candida albicans pseudohyphae. Because interactions between Candida and 


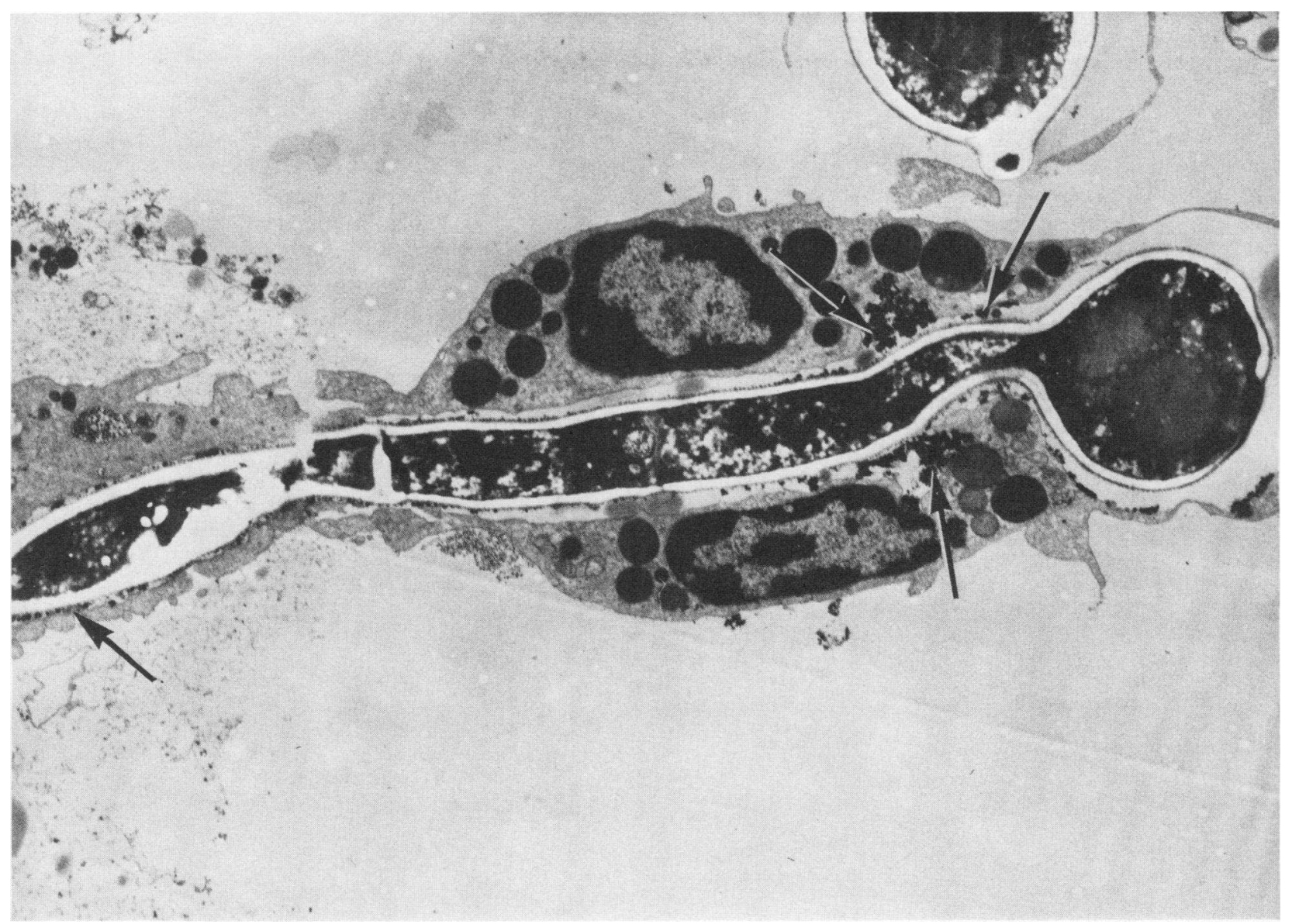

Figure 2 Electron micrograph taken after $60 \mathrm{~min}$ of, incubation of neutrophils with Candida albicans pseudohyphae. In this study, neutrophil granules had been labeled with ferritin, and excess ferritin was washed away. Ferritin (arrows) is located specifically surrounding the partially ingested pseudohypha, and nowhere else. Magnification $\times 11,800$.

neutrophils occurred in the absence of serum, it was possible that serum might not effect these interactions, or might increase or decrease damage to Candida by neutrophils. Using neutrophils from 17 normal subjects, autologous serum consistently increased the percentage. reduction of $\left[{ }^{14} \mathrm{C}\right]$ cytosine uptake by Candida $(P<0.001$ by twotailed two-sample $t$ test) (Fig. 5). This occurred whether serum was fresh or heated at $56^{\circ} \mathrm{C}$ for $60 \mathrm{~min}$. When neutrophils were preincubated in serum and washed before exposure to Candida, there was no increment. However, with preincubation of Candida in serum followed by washing before incubation with neutrophils, there was augmentation of damage to Candida, comparable to that seen when serum was present throughout incubations (Fig. 5). Because opsonization of the organism by heated serum was as effective as fresh serum, it appeared that anti-Candida IgG might be involved rather than complement. Indirect fluorescent antibody determinations using fluorescein-conjugated
anti-IgG indicated faint $(1-2+/ 4+)$ fluorescence on Candida which had been incubated in normal sera diluted 1:1-1:16 in HBSS. Under the same conditions, there was no fluorescence on Candida surfaces using fluorescein-conjugated antialbumin or antibody to the third component of complement. However, when sera were tested for antiCandida antibodies using standard techniques for detection of agglutinins and precipitins, none were found. Purified preparations of human IgG were used to determine if low levels of anti-Candida activity might be present in immunoglobulins in normal sera. When three different preparations of normal human IgG were added to incubations containing Candida and neutrophils, an increment in opsonization was seen $(P<0.05)$, similar to that noted when whole serum was used (Fig. 5). To establish further that low levels of antiCandida IgG were interacting with neutrophil $\mathrm{Fc}$ receptors, attempts were made to block activity of antiCandida IgG. Heat aggregation of $\operatorname{IgG}(P<0.01)$ or the 


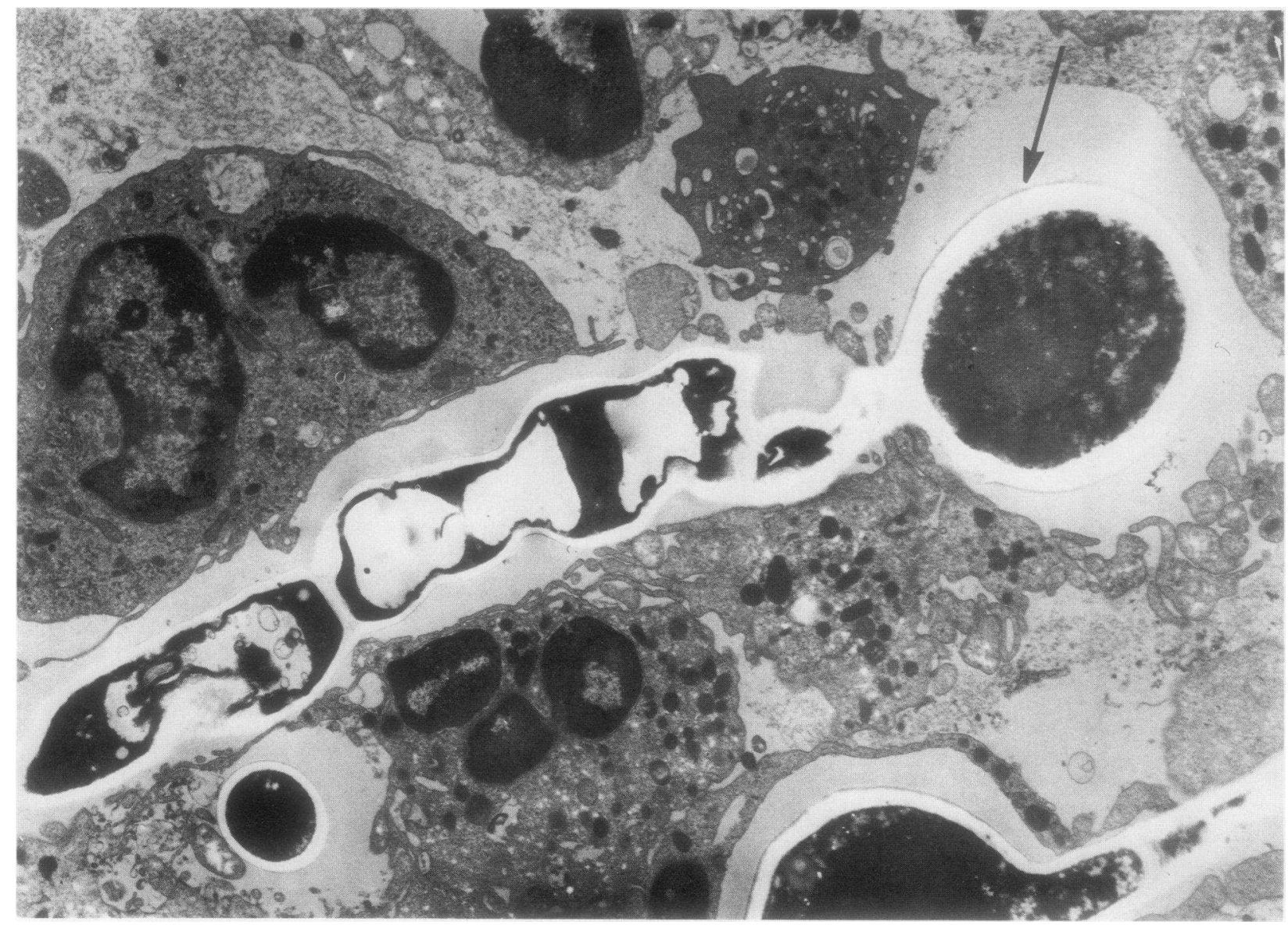

FIGURE 3 Electron micrograph taken after $60 \mathrm{~min}$ of incubation of neutrophils with Candida albicans pseudohyphae, showing changes in cell wall (arrows) and loss of discernable internal morphology of Candida, which is between several neutrophils. Magnification $\times 5,265$.

presence of rheumatoid factor $(P<0.025)$ in serum (34) both eliminated the increments in opsonization normally seen with IgG or whole serum, as did absorption of IgG with Candida.

Unlike serum, removal of divalent cations from the medium completely inhibited interactions of neutrophils with Candida albicans pseudohyphae. In two experiments in HBSS, neutrophils reduced uptake of $\left[{ }^{14} \mathrm{C}\right]-$ cytosine into Candida by $83 \%$. However, when $10 \mathrm{mM}$ sodium citrate was added to HBSS, or a calcium and magnesium-free buffer (modified Hanks' solution) was substituted for HBSS, there was no reduction in uptake of $\left[{ }^{14} \mathrm{C}\right]$ cytosine into Candida.

Effect of inhibitors of neutrophil function on damage to Candida albicans pseudohyphae. Inhibitors were used which were known to be active in inhibiting the function of neutrophils with several microorganisms. The results were calculated as percent inhibition of the $\left[{ }^{14} \mathrm{C}\right]$ cytosine assay. Several concentrations of each inhibitor were tested. Concentrations of inhibitors were eliminated from studies if they inhibited uptake of $\left[{ }^{14} \mathrm{C}\right]$ cytosine in control incubations of Candida without neutrophils or if they caused $\geq 5 \%$ decrease in viability of neutrophils, as judged by phase contrast microscopy and by trypan blue exclusion, as well as ${ }^{51} \mathrm{Cr}$ release in selected studies. The most effective concentration of each inhibitor was then determined.

Colchicine, cytochalasin B, and 2-deoxyglucose inhibited the nonphagocytic interaction of neutrophils with Candida pseudohyphae (Table I). Dibutyryl cyclic AMP, and two compounds known to raise intracellular levels of cyclic AMP, theophylline and isoproterenol, all inhibited damage to Candida albicans pseudohyphae by neutrophils. With these compounds, there were no apparent morphologic changes which were attributable to the inhibitors on review of Giemsa-stained slides of interactions of neutrophils and Candida. Hydrocortisone, along with other steroid hormones and metabolites of hormones for comparison were also tested. Hydrocortisone and estriol had the highest inhibitory activity of all the 


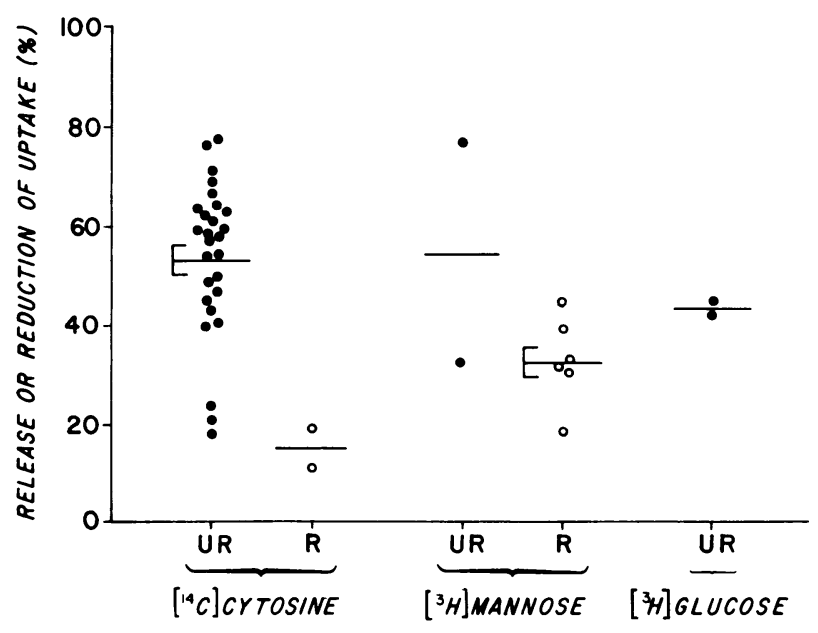

Figure 4 Effect of neutrophils on uptake and release of radioisotopes by Candida albicans pseudohyphae. Radiolabeled compounds are noted on the horizontal axis, with results for reduction in uptake of isotopes (UR), and isotope release (R). Percentage of uptake or release of isotopes is shown on the ordinate. Each point represents the mean of one or more experiments performed in triplicate on one normal individual. Horizontal lines denote means and brackets SEM for sets of observations. Experiments were performed using optimum numbers of neutrophils, and an optinum duration of incubations.

compounds which were tested (Table I). Testosterone had less inhibitory activity, whereas other steroids tested had little or no inhibitory activity.

Release of contents of neutrophil granules during contact with Candida pseudohyphae. Because degranulation was observed microscopically, quantitative studies were performed. A ratio of neutrophils to Candida of 1:1 gave optimum release of lysosomal enzymes $\beta$-glucuronidase and $N$-acetyl- $\beta$-D-glucosaminidase from neutrophils. There was only a slight but significant $(P<0.05$ by two-sample $t$ test $)$ release of lysosomal enzymes by neutrophils (Table II), though microscopic observations indicated that over $90 \%$ of neutrophils were attached to Candida. Hydrocortisone, in the concentration which completely blocked damage to Candida as measured by the $\left[{ }^{14} \mathrm{C}\right]$ cytosine assay, did not inhibit this small amount of release of granule enzymes from neutrophils. This was confirmed in fluorescence microscopic studies. In contrast, lysozyme was released in larger amounts during incubations with pseudohyphae $(P$ $<0.001$ ) (Table II). Hydrocortisone also did not inhibit lysozyme release.

Live vs. killed Candida albicans pseudohyphae in iodination of Candida and stimulation of chemiluminescence by neutrophils. In light microscopic studies, it was noted that neutrophils did not readily attach to killed pseudohyphae. Therefore, iodination of pseudohyphae and chemiluminescence by neutrophils in response to interaction with pseudohyphae were evaluated, to determine if these processes were activated by surface attachment of neutrophils to pseudohyphae in the absence of serum, and whether live fungi were required. In the absence of serum, neutrophils actively iodinated live Candida albicans (Table III). In contrast, iodination was markedly reduced when pseudohyphae were used which had been killed by heat or ultraviolet light. Comparable results were obtained in measurements of chemiluminescence. Live Candida stimulated chemiluminescence. by neutrophils even when serum was not present in incubations (Fig. 6). However, killed pseudohyphae did not stimulate chemiluminescence.

Interaction of fungi other than Candida pseudohyphae with neutrophils. In order to determine the specificity of the interaction between Candida pseudohyphae and neutrophils, other live fungi were tested. By phase contrast microscopic observation, in the absence of serum, only 5-8\% of Candida yeasts were ingested by neutrophils, and only $\cong 5 \%$ of the yeasts were attached to the surfaces of neutrophils. The encapsulated yeast, Cryptococcus neoformans, was not ingested by neutrophils at all in the ab-

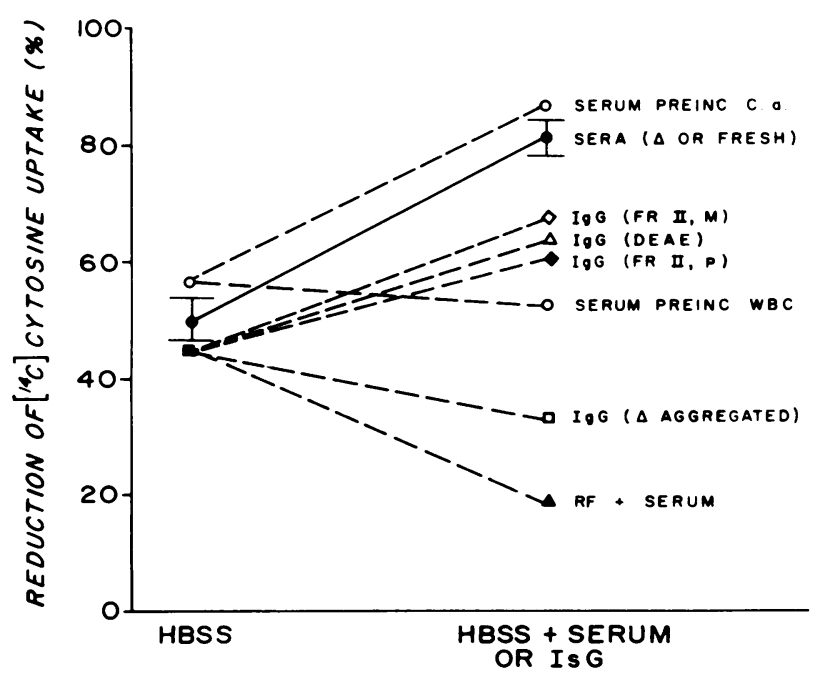

Figure 5 Effect of serum and IgG on opsonization of live Candida albicans pseudohyphae. Interaction of Candida with neutrophils is measured by neutrophil-induced reduction of uptake of $\left[{ }^{1+} \mathrm{C}\right]$ cytosine by Candida, shown on the ordinate. Each point represents the mean of at least two experiments, each performed in triplicate. Results are shown using buffer (HBSS) alone. The solid line connects mean and SEM values for experiments performed in HBSS with those performed with $10 \%$ heated $(\triangle)$ or fresh serum from 17 normal subjects. Shown separately, connected to results in controls by dotted lines, are results of preincubation of Candida albicans (PREINC C.a.) or neutrophils (PREINC WBC) in serum, which was washed away before incubations. Also shown separately are results using two commerical (FR II,M; FR II,P) and one freshly purified (DEAE) preparations of IgG, as well as heat $(\triangle)$ aggregated IgG, and sera containing rheumatoid factor $(\mathrm{RF}+)$. 
TABLE I

Effect of Inhibitors of Neutrophil Function on Reduction of Cytosine Uptake by Candida albicans Pseudohyphae

\begin{tabular}{lr}
\hline \multicolumn{1}{c}{ Inhibitor (concentration added) } & Inhibition* \\
\hline & $\%$ \\
Colchicine $(0.1 \mathrm{mM})$ & 62.1 \\
Cytochalasin $\mathrm{B}(2 \mu \mathrm{g} / \mathrm{ml}) \downarrow$ & 44.7 \\
Cytochalasin $\mathrm{B}(20 \mu \mathrm{g} / \mathrm{ml}) \ddagger$ & 57.6 \\
2-Deoxyglucose $(0.2 \mathrm{mM})$ & 100.0 \\
2-Deoxyglucose $(0.2 \mathrm{mM})+$ glucose $(2 \mathrm{mM})$ & 0.0 \\
Dibutyryl cyclic $\mathrm{AMP}(1 \mathrm{mM})$ & 42.8 \\
Theophylline $(1 \mathrm{mM})$ & 48.1 \\
Isoproterenol $(1 \mathrm{mM})$ & 65.2 \\
Hydrocortisone $(1 \mu \mathrm{M}) \S$ & 34.6 \\
Hydrocortisone $(10 \mu \mathrm{M})$ & 100.0 \\
Estriol $(1 \mu \mathrm{M})$ & 69.9 \\
Estriol $(10 \mu \mathrm{M})$ & 100.0 \\
Testosterone $(10 \mu \mathrm{M})$ & 48.5 \\
Androsterone $(10 \mu \mathrm{M})$ & 14.3 \\
Progesterone $(10 \mu \mathrm{M})$ & 0.0 \\
Dehydroisoandrosterone $(10 \mu \mathrm{M})$ & 2.3 \\
$17 \alpha$-Hydroxyprogesterone $(10 \mu \mathrm{M})$ & 10.5 \\
\hline
\end{tabular}

* Calculated from the results of $\left[{ }^{14} \mathrm{C}\right]$ cytosine uptake in the presence and absence of inhibitors. Values represent means of at least two separate experiments, each performed in triplicate.

f Controls contained equivalent concentrations of dimethylsulfoxide.

$\$$ Controls for all corticosteroids contained equivalent concentrations of ethanol.

sence of serum, nor was there close surface contact between neutrophils and yeasts. In contrast, Rhizopus oryzae and Aspergillus fumigatus became covered with neutrophils spreading over the surfaces of

TABLE II

Selective Release of Markers of Azurophil and Specific Granules of Neutrophils During Interaction with Candida Pseudohyphae

\begin{tabular}{|c|c|c|c|c|c|}
\hline \multicolumn{3}{|c|}{ Present in incubation } & \multicolumn{3}{|c|}{ Release* $^{*}$} \\
\hline \multirow[t]{2}{*}{$\begin{array}{c}\text { Neutro- } \\
\text { phils }\end{array}$} & Candida $\S$ & $\begin{array}{c}10 \mu \mathrm{M} \\
\text { Hydro- } \\
\text { cortisone }\end{array}$ & $\begin{array}{l}\beta \text {-Glucuron- } \\
\text { idase }\end{array}$ & $\begin{array}{c}N \text {-Acetyl- } \beta \text { - } \\
\text { D-gluco- } \\
\text { saminidase }\end{array}$ & Lysozyme \\
\hline & & & & $\%$ & \\
\hline Yes & No & No & $5.7 \pm 2.4$ & $3.6 \pm 0.6$ & $1.0 \pm 1.0$ \\
\hline Yes & Yes & No & $12.6 \pm 1.9$ & $11.1 \pm 1.1$ & $27.9 \pm 1.5$ \\
\hline Yes & No & Yes & $6.0 \pm 1.0$ & $3.6 \pm 1.1$ & $0.1 \pm 0.1$ \\
\hline Yes & Yes & Yes & $9.0 \pm 4.5$ & $13.6 \pm 2.2$ & $28.7 \pm 4.6$ \\
\hline
\end{tabular}

* Mean \pm SEM.

$\$$ Each tube contained $5 \times 10^{6}$ neutrophils.

$\S$ Each tube contained $5 \times 10^{6}$ Candida.
TABLE III

Effect of Viability of Candida albicans Pseudohyphae on Iodination of Candida by Neutrophils in the Absence of Serum

\begin{tabular}{lcc}
\hline \multicolumn{1}{c}{ Candida viability } & Iodination* & $\begin{array}{c}\text { Inhibition of } \\
\text { iodination }\end{array}$ \\
\hline & $\begin{array}{c}\text { nmol }{ }^{125} \text { I fixed per } \\
10^{7} \text { neutrophilsh }\end{array}$ & $\%$ \\
Live & 39.8 & - \\
Heat killed & 9.0 & 76.8 \\
Ultraviolet-light killed & 13.2 & 66.0 \\
\hline
\end{tabular}

* Mean of three experiments, each performed in triplicate.

hyphae. These observations were confirmed and better quantitated using iodination of these fungi by neutrophils in the presence and absence of serum (Table IV). Dose-response curves were performed for each organism, and the concentration which gave maximum iodination was used. Like Candida pseudohyphae, Rhizopus and Aspergillus were iodinated in the absence of serum, and showed an increment in iodination when serum was present. The encapsulated yeast, Cryptococcus neoformans, was iodinated significantly only when serum was present. Candida yeasts, even in increased numbers to account for differences in surface area, were not iodinated as much as Candida pseudohyphae.

\section{DISCUSSION}

These experiments have established that neutrophils can damage and probably kill Candida pseudohyphae. Pseudohyphae were too large to be completely ingested by neutrophils. Nevertheless, neutrophils at-

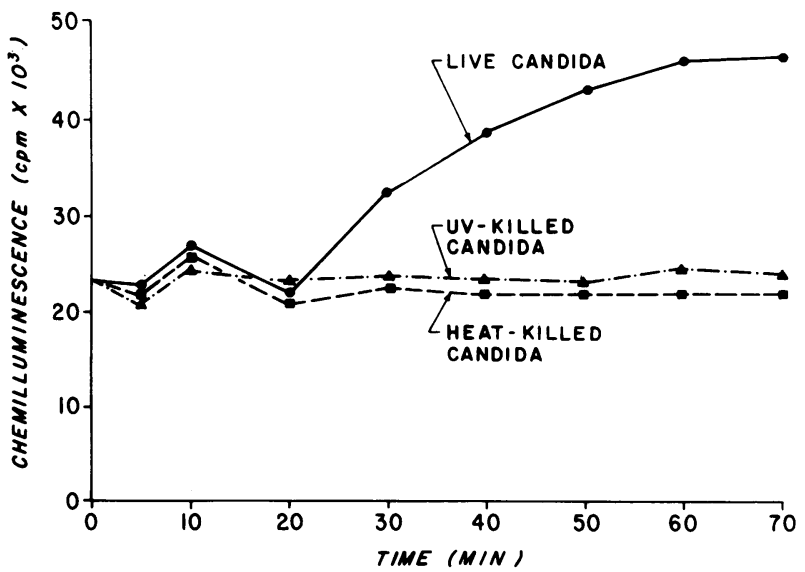

FIGURE 6 Effect of viability of Candida albicans pseudohyphae on chemiluminescence by neutrophils induced on contact with Candida in the absence of serum. Results using live Candida are compared with those using Candida killed by heat or ultraviolet (UV) light. 
TABLE IV

Iodination of Fungi by Neutrophils in the Presence and Absence of Autologous Serum

\begin{tabular}{llc}
\hline \multicolumn{1}{c}{ Fungus* (growth phase) } & $\begin{array}{c}\text { Serum in } \\
\text { incubations }\end{array}$ & Iodination \\
\hline & & $\begin{array}{c}\text { nmol }{ }^{125} \text { f fixed per } \\
10^{7} \text { neutrophilsh }\end{array}$ \\
Candida albicans (pseudohyphae) & No & 50.6 \\
& Yes & 94.9 \\
Candida albicans (yeasts) & No & 10.0 \\
& Yes & 21.7 \\
Cryptococcus neoformans (yeasts) & No & 0.5 \\
& Yes & 14.2 \\
Rhizopus oryzae (hyphae) & No & 24.9 \\
& Yes & 86.6 \\
Aspergillus fumigatus (hyphae) & No & 65.4 \\
& Yes & 96.3 \\
\hline
\end{tabular}

* Each tube contained $5 \times 10^{6}$ fungi with $1 \times 10^{7}$ neutrophils, except for Candida yeasts, where $5 \times 10^{7}$ tube were required for maximum iodination.

tached to and spread over the surfaces of pseudohyphae. Morphologic changes occurred in the Candida, as judged by light, phase contrast, and electron microscopic observations. Dramatic changes in the Candida cell wall by electron microscopy were similar to those described by others who observed organisms in tissues of infected mice or human patients (35) or in vitro with leukocytes (36). The significance of these morphologic changes was confirmed by parallel studies using radioisotopically labeled nutrients. These experiments indicated that metabolism of Candida was impaired after contact with neutrophils, and that Candida labeled with radioisotopes of cytosine or mannose released these compounds during incubations with neutrophils. Because conventional methods for quantitating viability of fungi could not be used with pseudohyphae, it remains possible that metabolic damage to Candida pseudohyphae was reversible. However, the concomitant striking morphologic changes suggested fungal cell death. In addition, even in the fungi were not killed, damage to hyphae which are too large to be ingested by phagocytic cells might still be an important host defense mechanism. This capability of neutrophils may be especially important because the large pseudohyphal and hyphal forms of Candida are predominant in lesions in tissues $(4,5)$ which contain both large and small forms of Candida. There have been many studies on interactions of Candida blastospores (or yeasts) with leukocytes $(9-13,23)$. However, in addition to morphologic differences between forms of Candida, antigens (37) and other properties may not be identical. Our ex- periments indicated several differences between Candida yeasts and pseudohyphae in interaction with neutrophils.

First, interactions between Candida pseudohyphae and neutrophils required no serum. In the presence of serum, there was an increment in contact between Candida and neutrophils, and damage to Candida increased. This effect was duplicated by normal human IgG, was blocked by heat aggregation of $\operatorname{IgG}$ or by sera which contained rheumatoid factor (34), and appeared to be attributable to opsonization of Candida by low levels of anti-Candida IgG which was present in normal human sera. This is consistent with the observations of Weiner and Yount (38), who found that antibodies to Candida mannan were universally present in sera from adult normal control subjects.

Despite the absence of serum, interactions of neutrophils with Candida pseudohyphae appeared to activate leukocyte microbicidal mechanisms, as evidenced by studies of iodination and chemiluminescence. Iodination of microorganisms generally occurs after phagocytosis, with interaction of myeloperoxidase and hydrogen peroxide within phagocytic vacuoles (39). The light emission in chemiluminescence of neutrophils has been correlated with the production of oxidizing agents by phagocytosing neutrophils (40). For microorganisms, this also requires either the presence of serum opsonins, or opsonization of organisms by incubation with serum prior to incubation with neutrophils (41). In contrast, Candida pseudohyphae required neither complete ingestion nor serum opsonins to be iodinated by neutrophils or induce neutrophils to chemiluminesce.

Iodination (28) and chemiluminescence (41) have both been used as sensitive screening techniques for abnormalities in the phagocytic process. Similarly, the occurrence of iodination and chemiluminescence during incubations of neutrophils with Candida pseudohyphae provided useful procedures for quantitation of surface interactions between fungi and leukocytes, which correlated well with light microscopic studies. These studies suggested that surface factors are present on live but not killed fungi which permit recognition by leukocytes. These factors were not limited to Candida pseudohyphae, as Rhizopus oryzae and Aspergillus fumigatus were iodinated in the absence of serum, and became attached to neutrophils on microscopic examination. In contrast, iodination of Candida yeasts was less than iodination of pseudohyphae, and Cryptococcus neoformans, where the yeast cell wall is covered by a capsule, was iodinated significantly only when serum was present. Consequently, it appears possible that the capacity of fungi to interact with leukocytes in the absence of serum may reflect a general property of cell walls of large forms of fungi. 
Further insights were gained into interactions between Candida pseudohyphae through the use of substances which are known to inhibit neutrophil function. Several inhibitors of neutrophil phagocytic and other functions also inhibited nonphagocytic damage to Candida pseudohyphae. Damage to pseudohyphae by neutrophils was inhibited by colchicine, cytochalasin $\mathrm{B}$, and 2-deoxyglucose. Colchicine is known to inhibit function of neutrophil microtubules, and may inhibit phagocytosis under some conditions as well (42). Cytochalasin B inhibits neutrophil microfilaments and blocks phagocytosis, but also causes exocytosis of lysosomal hydrolases from neutrophils, and inhibits hexose transport (43). The compound 2-deoxyglucose inhibits aerobic and anaerobic cellular metabolism as well as phagocytosis, though inhibition of phagocytosis may occur by a separate mechanism (44). Dibutyryl cyclic AMP, theophylline, and isoproterenol, all of which elevate intracellular levels of $3^{\prime} 5^{\prime}$ cyclic AMP in neutrophils, inhibited damage to Candida pseudohyphae without clearly interfering with surface contact or spreading over surfaces of Candida. Elevated levels of cyclic AMP have been shown to inhibit several functions of neutrophils, such as phagocytosis, release of lysosomal enzymes, and killing of microorganisms, including Candida yeasts (45). Because microscopic observations indicated that neutrophils degranulated during contact with pseudohyphae, the effects of hydrocortisone were then studied. Besides the well-known association between corticosteroid therapy and invasive candidiasis $(4,5)$, cortisone may inhibit release of lysosomal enzymes from neutrophils (46). Hydrocortisone inhibited damage to Candida pseudohyphae by neutrophils at levels $(10-1 \mu \mathrm{M})$ which may be reached in vivo after pharmacologic doses. Nevertheless, there was no visible or quantitative inhibition of degranulation of neutrophils by hydrocortisone. Hydrocortisone appeared to inhibit damage to pseudohyphae by inhibiting a neutrophil mechanism other than degranulation.

Despite the visual evidence for degranulation of neutrophils during contact with pseudohyphae, there was only minimal quantitative release of two lysosomal enzymes from neutrophils. In contrast, lysozyme was released in much larger amounts. Within neutrophils, lysosomal enzymes are located in the azurophil granules, while lysozyme is present in the specific granules, which appear to discharge first (47). Contact between neutrophils and pseudohyphae may provide a less complete stimulus for degranulation than phagocytosis, so that contents of specific granules are released preferentially.

Further experiments will be required to delineate which mechanism is primarily responsible for metabolic and morphologic damage to Candida pseudohyphae by neutrophils. In addition, neutrophils directly recognize Candida pseudohyphae and other fungi and activate cellular microbicidal mechanisms in the absence of serum opsonins by a mechanism which must be characterized, although the interaction is enhanced by serum. Although the biologic importance of this new neutrophil mechanism remains to be determined, these experiments have established the utility of new methodology which permits quantitative studies of the interactions between neutrophils and large forms of pathogenic fungi.

\section{ACKNOWLEDGMENTS}

We wish to thank Dr. Robert A. Clark for helpful advice, Dr. Philip Davies for helpful discussion and for performing measurements of lysosomal enzymes, and Drs. Frederick Auletta, Arthur Schneider, and Clarence Gantt for supplying some of the reagents used in these studies. Hilda Sanders, Martha Newbill, and Jean Makowski provided invaluable technical assistance with the electron microscopic studies.

This work was supported by grant 12145 from the National Institute of Allergy and Infectious Disease of the National Institutes of Health.

\section{REFERENCES}

1. Chang, H., V. Rodriguez, G. Narboni, G. P. Bodey, M. A. Luna, and E. J. Freiereich. 1976. Causes of death in adults with acute leukemia. Medicine (Baltimore). 55: 259268.

2. Rose, H. D., and B. Varkey. 1975. Deep mycotic infection in the hospitalized adult: a study of 123 patients. Medicine (Baltimore). 54: 499-507.

3. Young, R. C., J. E. Bennett, G. W. Geelhoed, and A. S. Levine. 1974. Fungemia with compromised host resistance: a study of 70 cases. Ann. Intern. Med. 80: 605-612.

4. Emmons, C. W., C. H. Binford, J. P. Utz, and K. J. KwonChung. 1976. Medical Mycology. Lea and Febiger, Philadelphia. 3rd edition. 192-196.

5. Rippon, J. W. 1974. Medical Mycology: the Pathogenic Fungi and the Pathogenic Actinomycetes. W. B. Saunders Co., Philadelphia. 191-195.

6. Hurley, D. L., and A. S. Fauci. 1975. Disseminated candidiasis. I. An experimental model in the guinea pig. J. Infect. Dis. 131: 516-521.

7. Louria, D. B., D. P. Stiff, and B. Bennett. 1962. Disseminated moniliasis in the adult. Medicine (Baltimore). 41 : 307-337.

8. Medoff, G., W. E. Dismukes, R. H. Meade, Ill, and J. M. Moses. 1972. A new therapeutic approach to Candida infections: a preliminary report. Arch. Intern. Med. 130: 241-245.

9. Lehrer, R. I. 1970. Measurement of candidiacidal activity of specific leukocyte types in mixed cell populations. I. Normal, myeloperoxidase-deficient, and chronic granulomatous disease neutrophils. Infect. Immun. 2: 42-47.

10. Lehrer, R. I., and M. J. Cline. 1969. Leukocyte myeloperoxidase deficiency and disseminated candidiasis. The role of myeloperoxidase in resistance to Candida infection. J. Clin. Invest. 48: 1478-1488.

11. Lehrer, R. I., and M. J. Cline. 1971. Leukocyte candidacidal activity and resistance to systemic candidiasis in patients with cancer. Cancer (Phila.). 27: 1211-1217.

12. Oh, M. K., G. E. Rodey, R. A. Good, R. A. Chilgren, and P. G. Quie. 1969. Defective candidacidal. capacity of polymorphonuclear leukocytes in chronic granu- 
lomatous disease of childhood. J. Pediatr. 75: 300-303.

13. Quie, P. G., and R. A. Chilgren. 1971. Acute disseminated and chronic mucocutaneous candidiasis. Semin. Hematol. 8: 227-242.

14. Bodey, G. P. 1966. Fungal infections complicating acute leukemia. J. Chronic Dis. 19: 667-687.

15. Diamond, R. D., and A. C. Allison. 1976. Nature of the effector cells responsible for antibody-dependent cell-mediated killing of Cryptococcus neoformans. Infect. Immun. 14: 716-720.

16. Land, G. A., W. C. McDonald, R. L. Stjernholm, and L. Friedman. 1975. Factors affecting filamentation in Candida albicans: changes in respiratory activity of Candida albicans during filamentation. Infect. Immun. 12: $119-127$.

17. Dabrowa, N., S. S. S. Taxer, and D. Howard. 1976. Germination of Candida albicans induced by proline. Infect. Immun. 13: 830-835.

18. Boyle, W. 1968. An extension of the ${ }^{51} \mathrm{Cr}$ release assay for the estimation of mouse cytotoxins. Transplantation (Baltimore). 6: 761-764.

19. Mickenberg, I. D., R. K. Root, and S. M. Wolff. 1970. Leukocyte function in hypogammaglobulinemia. J. Clin. Invest. 49: 1528-1538.

20. Böyum, A. 1968. Isolation of mononuclear cells by one centrifugation, and of granulocytes by combining centrifugation and sedimentation at lg. Scand. J. Clin. Lab. Invest. Suppl. 97: 77-89.

21. Stanworth, D. R. 1960. A rapid method of preparing pure gamma globulin. Nature (Lond.). 188: 156-157.

22. Preisler, H. D., H. F. Hasenclaver, A. A. Levitan, and E. S. Henderson. 1969. Serologic diagnosis of disseminated candidiasis in patients with acute leukemia. Ann. Intern. Med. 70: 19-30.

23. Lehrer, R. I., and M. J. Clin. 1969. Interaction of Candida albicans with human leukocytes and serum. J. Bacteriol. 98: 996-1004.

24. Lilien, D. L., J. L. Spivak, and I. D. Goldman. 1970. Chromate transport in human leukocytes. J. Clin. Invest. 49: $1551-1557$.

25. Allison, A. C. 1976. Fluorescence microscopy of lymphocytes and mononuclear phagocytes and the use of silica to eliminate the latter. In In Vitro Methods in CellMediated and Tumor Immunity. B. R. Bloom and J. R. David, editors. Academic Press, Inc., New York. 395-404.

26. Hart, P. D'Arcy, and M. R. Young. 1975. Interference with normal phagosome-lysosome fusion in macrophages, using ingested yeast cells and suramin. Nature (Lond.). 265: $47-49$.

27. Armstrong, J. A., and P. D'Arcy Hart. 1971. Response of cultured macrophages to Mycobacterium tuberculosis, with observations on fusion of lysosomes with phagosomes. J. Exp. Med. 134: 713-740.

28. Klebanoff, S. J., and R. A. Clark. 1977. Iodination by human polymorphonuclear leukocytes: a re-evaluation. $J$. Lab. Clin. Med. 89: 675-686.

29. Stjernholm, R. L., R. C. Allen, R. H. Steele, W. W. Waring, and J. A. Harris. 1973. Impaired chemiluminescence during phagocytosis of opsonized bacteria. Infect. Immun. 7: 313-314.

30. Talalay, P., W. H. Fishman, and C. Huggins. 1946. Chromogenic substrates. II. Phenolphthalein glucoronic acid as substrate for the assay of glucuronidase activity. J. Biol. Chem. 166: 757-772.

31. Woolen, J. W., R. Heyworth, and P. G. Walker. 1961. Studies on glucosaminidase. 3. Testicular $N$-acetyl- $\beta$ glucosaminidase and $N$-acetyl- $\beta$-galactosaminidase. Biochem. J. 78: $111-116$.
32. Parry, R. M., Jr., R. C. Chandan, and K. M. Shahani. 1965. A rapid and sensitive assay of muramidase. Proc. Soc. Exp. Biol. Med. 119: 384-389.

33. Dixon, W. J., and F. J. Massey. 1969. Introduction to Statistical Analysis. McGraw-Hill, Inc., New York. 3rd edition. 114-119.

34. R. P. Messner, T. Ladal, P. G. Quie, and R. C. Williams, Jr. 1968. Serum opsonin, bacteria, and polymorphonuclear leukocyte interactions in subacute bacterial endocarditis. Anti-globulin factors and their interaction with specific opsonins. J. Clin. Invest. 47: 1109-1120.

35. Taschdjian, C. L., E. F. Toni, K. C. Hsu, M. S. Seelig, M. B. Cuesta, and P. J. Kozinn. 1971. Immunofluorescent studies of Candida in human reticuloendothelial phagocytes: implications for immunogenesis and pathogenesis of systemic candidiasis. Am. J. Clin. Pathol. 56: 50-58.

36. LaForce, F. M., D. M. Mills, K. Iverson, R. Cousins, and E. D. Everett. 1975. Inhibition of leukocyte candidacidal activity by serum from patients with disseminated candidiasis. J. Lab. Clin. Med. 86: 657666.

37. Evans, E. G. V., M. D. Richardson, F. C. Odds, and K. T. Holland. 1973. Relevance of antigenicity of Candida albicans growth phases to diagnosis of systemic candidiasis. 1973. Br. Med. J. 4: 86-87.

38. Weiner, M. C., and W. J. Yount. 1976. Mannan antigenemia in the diagnosis of invasive Candida infections. J. Clin. Invest. 58: 1045-1053.

39. Root, R. K., and T. P. Stossel. 1974. Myeloperoxidasemediated iodination by granulocytes. Intracellular site of operation and some regulating factors. J. Clin. Invest. 53: 1207-1215.

40. Cheson, B. D., R. L. Christenson, R. Sperling, B. E. Kohler, and B. M. Babior. 1976. The origin of the chemiluminescence of phagocytosing granulocytes. $J$. Clin. Invest. 58: 789-796.

41. Grebner, J. V., E. L. Mills, B. H. Gray, and P. L. Quie. 1977. Comparison of phagocytic and chemiluminescence response of human polymorphonuclear neutrophils. $J$. Lab. Clin. Med. 89: 153-159.

42. Stossel, T. P., R. J. Masson, J. Hartwig, and M. Vaughan. 1972. Quantitative studies of phagocytosis by polymorphonuclear leukocytes: use of emulsion to measure the initial rate of phagocytosis. J. Clin. Invest. 41: 614-624.

43. Zigmond, S. H., and J. G. Hirsch. 1972. Effects of cytochalasin B on polymorphonuclear leukocyte locomotion, phagocytosis and glycolysis. Exp. Cell Res. 73: 383393.

44. Michl, J., D. J. Ohlbaum, and S. C. Silverstein. 1976. 2-deoxyglucose selectively inhibits $\mathrm{Fc}_{\mathrm{c}}$ and complement receptor-mediated phagocytosis in mouse peritoneal macrophages. II. Dissociation of the inhibitory effects of 2-deoxyglucose on phagocytosis and ATP generation. J. Exp. Med. 144: 1484-1493.

45. Bourne, H. R., R. I. Lehrer, M. J. Cline, and K. L. Melmon. 1971. Cyclic 3'5'-adenosine monophosphate in the human leukocyte: synthesis, degradation, and effects on neutrophil candidacidal activity. J. Clin. Invest. 50: 920-929.

46. Ignarro, L. J. 1977. Glucorticosteroid inhibition of nonphagocytic discharge of lysosomal enzymes from human neutrophils. Arthritis Rheum. 19: 73-83.

47. Bainton, D. F. 1973. Sequential degranulation of the two types of polymorphonuclear leukocyte granules during phagocytosis of microorganisms. J. Cell. Biol. 58: 249-264. 